\title{
CUSTO DE PRODUÇÃO DE MUDAS CÍTRICAS NO MUNÍCIPIO DE MONTE AZUL PAULISTA NO ANO DE 2004
}

ORIOLI JÚNIOR, Valdeci ${ }^{1}$

TARSITANO, Maria Aparecida Anselmo²

COSTA, Roberto Savério Souza ${ }^{3}$

FONSECA, Antônio Eduardo ${ }^{3}$

\begin{abstract}
RESUMO: Tendo em vista a falta de informações sobre aspectos econômicos da produção de mudas cítricas e a relevante importância destas para a citricultura nacional, o presente trabalho tem como objetivo avaliar o custo de produção de mudas cítricas em ambiente protegido, sendo um caso específico o de um produtor do município de Monte Azul Paulista - SP. A estrutura para o custo de formação baseou-se naquela que vem sendo adotada pelo Instituto de Economia Agrícola. Nessa estrutura, o custo operacional efetivo envolve: mão-de-obra, maquinaria, combustíveis, lubrificantes, materiais consumidos (sementes e/ou mudas, adubos, defensivo etc), ou seja, soma das despesas diretas. O custo operacional total inclui o custo operacional efetivo mais as despesas indiretas como: depreciação dos bens duráveis e encargos sociais. Analisando os resultados do trabalho, pode-se concluir que a produção de mudas cítricas no município de Monte Azul Paulista mostra-ser uma atividade rentável, tendo, portanto, um custo de produção satisfatório e uma relação benefício maior que a relação custo.
\end{abstract}

Palavras-chave: Ambiente protegido. Citros. Análise econômica.

\section{COST OF ORANGE TREES PRODUCTION IN MONTE AZUL PAULISTA CITY IN 2004}

SUMMARY: Observing Seen the lack of information about economic aspects of the great orange trees production and the importance of this for the national production of citric fruits, the present work has, as objective, to evaluate the cost of production of orange trees in protected environment, being a specific case a producer of Monte Azul Paulista city-SP. The structure for the formation cost was based in one that has being adopted by IEA. In this structure, the effective operational cost involves: man-power, schemes, consumed fuels, lubricant, materials (seeds and/or orange trees, seasonings, defensive, etc), that is, the addition of the direct expenditures. The total operational cost includes the effective operational cost and the indirect expenditures as: depreciation of the durable goods and social changes. Analyzing the results of the work, it may be concluded that the production of orange trees in Monte Azul Paulista city reveals an income-producing activity, having, therefore, a satisfactory cost of production and a relation benefit than relation cost.

Keywords: Protected environment. Citrus great. Economic analysis.

\section{INTRODUÇÃO}

No momento, em São Paulo, tanto produtores como industriais têm consciência, quase generalizada, de que o aumento da produtividade média e da vida útil (longevidade) dos 1 Eng. Agrônomo, Mestrando, Depto. Solos e Adubos, UNESP/Jaboticabal - SP. E-mail: orioli.jr@hotmail.com

2 Prof ${ }^{a}$ Dr$^{\mathrm{a}}$ Dpto. Fitotecnia, Tecnologia de Alimentos e Sócio-Economia, UNES/ Ilha Solteira - SP. 3 Eng. Agrônomo. 
pomares será fator decisivo para manter a posição de liderança mundial e permitir expandir os mercados consumidores de suco de laranja, principalmente, diante da crescente concorrência e da expectativa de preços deprimidos pelo excesso de oferta.

No caso do comércio de fruta fresca para exportação ou para consumo no mercado interno brasileiro, além dos aspectos quantitativos, deve haver, também, maior preocupação com a qualidade, tamanho e aparência das frutas, o que torna a questão ainda mais complexa.

Evidentemente, a produtividade é função de vários fatores fixos e outros variáveis que podem ser controlados ou modificados pelo citricultor, principalmente, na fase de implantação do pomar. É óbvio, também, que, em um pomar já estabelecido, algumas modificações são praticamente inviáveis, como, por exemplo, as variedades de copas.

Com a chegada da doença Clorose Variegada dos Citros (CVC) na década de 80, trazendo sérios prejuízos para o setor, e com a constatação de que a CVC e outras doenças e pragas estavam sendo disseminadas por mudas contaminadas já nos viveiros, a questão da escolha do material de propagação ganhou maior importância e precisa ser melhor analisada economicamente pelos citricultores, pelos produtores de mudas (viveiristas) e pelas autoridades governamentais (REVISTA DO FUNDECITRUS, 1998-2000). Mais recentemente (1998), com apoio do FUNDECITRUS, a Secretaria de Agricultura e Abastecimento adotou medidas para conter o avanço da CVC, resultando em um novo Programa de Plantas Matrizes de Citros, com o objetivo de serem produzidas mudas certificadas de citros.

Tendo em vista a falta de informação sobre aspectos econômicos da produção de mudas cítricas e a relevante importância destas para a citricultura nacional atualmente, o presente trabalho tem como objetivo avaliar o custo de produção de mudas cítricas em ambiente protegido, sendo um caso específico, o de um produtor do município de Monte Azul Paulista-SP.

\section{MATERIAL E MÉTODOS}

O município de Monte Azul Paulista se encontra na região de Bebedouro, região esta, de grande importância para a citricultura paulista, possuindo considerável área cultivada com citros, grandes indústrias e estações experimentais, estando distanciada, aproximadamente, 400 km da capital.

Os dados foram adquiridos junto a um produtor rural do município de Monte Azul Paulista-SP. Os preços foram levantados junto à Cooperativa dos cafeicultores e citricultores de São Paulo (COOPERCITRUS).

Utilizou-se, apenas, uma variedade de porta-enxerto, o limão cravo (Citrus limonia Osbeck). Estes foram transplantados em recipientes com capacidade para quatro litros de substrato, sendo o substrato um composto de casca de pínus e vermiculita expandida da marca comercial Paraíso.

O tipo de enxertia foi a borbulhia, que é a mais utilizada para a produção de mudas cítricas. 
A irrigação era realizada de duas a três vezes por semana, variando em função das condições climáticas. Esta era realizada manualmente, por meio de um cano de PVC perfurado ligado a uma borracha conectada à saída da bomba hidráulica. O tanque para armazenamento de água tem capacidade para 2.000 litros de água.

As adubações, realizadas via irrigação, foram distribuídas da seguinte forma:

- $1^{\circ}$ aplicação: Calcinit (nitrato de cálcio) + Hidroferro.

- $2^{\circ}$ aplicação: Máster (mistura NPK).

- $3^{\circ}$ aplicação: Calcinit.

- $4^{\circ}$ aplicação: Ácido bórico + Sulfato de Mg + Sulfato de Zn + Sulfato de Mn + Krista$\mathrm{K}+\mathrm{MAP}$.

O intervalo entre uma aplicação e outra era o mesmo das irrigações, ou seja, de dois a três dias.

Já as adubações, realizadas por meio de pulverizador costal, foram distribuídas da seguinte maneira:

- Uma aplicação de Hidrocoquetel a cada sete dias.

- Uma aplicação de Megafol a cada 15 dias.

- Uma aplicação de Viva a cada 15 dias.

Vale ressaltar que as aplicações foram realizadas em momentos distintos, ou seja, foram intercaladas. Primeiramente, aplicou-se o Hidrocoquetel; dois dias após, aplicou-se Megafol e, cinco dias após esta última aplicação, aplicou-se novamente o Hidrocoquetel, completando sete dias após a primeira aplicação. Logo após, passados dois dias, foi realizada a aplicação de Viva e, assim, sucessivamente, completando os intervalos entre as aplicações que foram supracitados.

As aplicações de fungicidas e inseticidas foram realizadas de maneira preventiva, sendo feitas uma vez por semana.

A poda de formação foi realizada de maneira que restassem três brotos por planta, escolhendo-se os mais vigorosos.

Foram produzidas 16.000 mudas da variedade "Pêra", 4.000 mudas da variedade "Natal" e 4.000 mudas da variedade "Valência".

A estrutura para o custo de formação baseou-se naquela que vem sendo adotada pelo IEA (MATSUNAGA, 1970). Nessa estrutura de custo, o custo operacional efetivo (COE) envolve: mão-de-obra, maquinaria, combustíveis, lubrificantes, materiais consumidos (sementes e/ou mudas, adubos, defensivo, etc), ou seja, pela soma das despesas diretas. O custo operacional total (COT) inclui o $\mathrm{COE}$ e as despesas indiretas como: depreciação dos bens duráveis e encargos sociais.

A conversão de valores em moeda corrente no País foi feita com uso das taxas oficiais de câmbio divulgadas pela FGV.

Nucleus, v. 5. n. 1 , abr. 2008 


\section{RESULTADOS E DISCUSSÃO}

A estrutura de custo de produção está representada na tabela 01, e o índice de lucratividade está representado na tabela 02 .

O custo total de produção de mudas cítricas foi de $\mathrm{R} \$ 32.051,47$. O custo mais elevado é o gasto com materiais que representa $51,73 \%$ do custo total de produção.

Percebe-se que os fatores básicos para a produção de mudas cítricas (substrato, borbulhas e porta-enxerto) representam os maiores custos, sendo estes responsáveis por $43,43 \%$ do custo total de produção. Quanto ao custo de produtos referentes às aplicações de defensivos e adubações, este representa $7,26 \%$ do custo total.

Observando-se os valores referentes às operações manuais, verifica-se que os fatores que mais oneram a produção são as adubações, as irrigações e a enxertia, sendo responsáveis, respectivamente, por $27,43 \%, 18,28 \%$ e $15,24 \%$ do custo das operações manuais, e a somatória destes representa $14,97 \%$ do custo total de produção.

A assistência técnica teve como remuneração $2 \%$ do valor da renda bruta.

A depreciação da estrutura de produção das mudas foi calculada, considerando que o valor final do viveiro, após uma vida útil de 10 anos, seja $20 \%$ do valor inicial deste, que é R\$ $35.000,00$, tendo este, 2 anos de uso até o momento.

Tabela 1: Estrutura do custo de formação de 24.000 mudas cítricas no município de Monte Azul Paulista-SP, no ano de 2004.

(Continua)

\begin{tabular}{|c|c|c|c|c|c|}
\hline \multicolumn{6}{|l|}{ CUSTO DE PRODUCÃO } \\
\hline \multicolumn{6}{|l|}{ Cultura: Mudas cítricas } \\
\hline \multicolumn{6}{|l|}{ Produtividade: unidades } \\
\hline \multirow{3}{*}{\multicolumn{6}{|c|}{$\begin{array}{l}\text { Ano: } 2004 \\
\text { Produção: } 24.000 \\
\text { Valor atual do dólar }=2,60\end{array}$}} \\
\hline & & & & & \\
\hline & & & & & \\
\hline DESCRIÇÃO & Especif. & V. unit. & Qtd. & Total & Total \\
\hline \multicolumn{6}{|l|}{ A - OPERACCÕES MANUAIS } \\
\hline Enchimento dos recipientes (x7) & DH & 15,00 & 7,00 & 735,00 & $1.911,00$ \\
\hline Transplante (x4) & DH & 15,00 & 6,00 & 360,00 & 936,00 \\
\hline Irrigação (x2) & $\mathrm{DH}$ & 15,00 & 48,00 & $1.440,00$ & $3.744,00$ \\
\hline Tutoragem $(\mathrm{x} 3)$ & $\mathrm{DH}$ & 15,00 & 8,00 & 360,00 & 936,00 \\
\hline Enxertia (x3) & enxerto & 0,05 & $24.000,00$ & $1.200,00$ & $3.120,00$ \\
\hline Aplicação de inseticida (x2) & DH & 15,00 & 24,00 & 720,00 & $1.872,00$ \\
\hline Adubação (x2) & $\mathrm{DH}$ & 15,00 & 72,00 & $2.160,00$ & $5.616,00$ \\
\hline Poda de formação (x2) & DH & 15,00 & 24,00 & 300,00 & 780,00 \\
\hline Produção de estacas (x2) & DH & 15,00 & 16,00 & 480,00 & $1.248,00$ \\
\hline Poda de ponteiros (x2) & $\mathrm{DH}$ & 15,00 & 4,00 & 120,00 & 312,00 \\
\hline Subtotal A & & & & $7.875,00$ & $20.475,00$ \\
\hline \multicolumn{6}{|l|}{ B - MATERIAL } \\
\hline Substrato & $\mathrm{m}^{3}$ & 100,00 & 60,00 & $6.000,00$ & $15.600,00$ \\
\hline Recipientes & unid. & $24.000,00$ & 0,01 & 240,00 & 624,00 \\
\hline Borbulhas & unid. & $24.000,00$ & 0,15 & $3.600,00$ & $9.360,00$ \\
\hline
\end{tabular}


Tabela 1: Estrutura do custo de formação de 24.000 mudas cítricas no município de Monte Azul Paulista-SP, no ano de 2004.

\begin{tabular}{|c|c|c|c|c|c|}
\hline Fitilho & 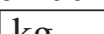 & & 1100 & & 15720 \\
\hline Rolo plástico (grampeador) & unid. & 80,00 & 3,00 & 24,00 & 62,40 \\
\hline Grampos & $\mathrm{cx}$ & 5,00 & 2,00 & 10,00 & 26,00 \\
\hline Porta-enxerto & unid. & $24.000,00$ & 0,18 & $4.320,00$ & $11.232,00$ \\
\hline Tedion & $\mathrm{L}$ & 28,71 & 2,00 & 57,42 & 149,29 \\
\hline Supracid & $\mathrm{L}$ & 38,48 & 2,00 & 76,96 & 200,10 \\
\hline Vertimec & $\mathrm{L}$ & 120,67 & 2,00 & 241,34 & 627,48 \\
\hline Decis & $\mathrm{L}$ & 56,65 & 3,00 & 169,95 & 441,87 \\
\hline Adubo MAP & $\mathrm{kg}$ & 2,704 & 125,00 & 338,00 & 878,80 \\
\hline Adubo Uréia & $\mathrm{kg}$ & 0,998 & 50,00 & 49,90 & 129,74 \\
\hline Adubo Krista - K & $\mathrm{kg}$ & 1,975 & 25,00 & 49,38 & 128,38 \\
\hline Adubo Sulfato de $\mathrm{Mg}$ & $\mathrm{kg}$ & 0,49 & 25,00 & 12,25 & 31,85 \\
\hline Adubo Sulfato de Zn & $\mathrm{kg}$ & 1,24 & 25,00 & 31,00 & 80,60 \\
\hline Adubo Sulfato de Mn & $\mathrm{kg}$ & 1,42 & 50,00 & 71,00 & 184,60 \\
\hline Adubo Sulfato de $\mathrm{Cu}$ & $\mathrm{kg}$ & 1,29 & 25,00 & 32,25 & 83,85 \\
\hline Fertilizante Ácido Bórico & $\mathrm{kg}$ & 1,94 & 25,00 & 48,50 & 126,10 \\
\hline Fertilizante Calcinit & $\mathrm{kg}$ & 1,76 & 150,00 & 264,00 & 686,40 \\
\hline Fertilizante Master & $\mathrm{kg}$ & 3,62 & 50,00 & 181,00 & 470,60 \\
\hline Fertilizante Megafol (via foliar) & $\mathrm{L}$ & 25,10 & 5,00 & 125,50 & 326,30 \\
\hline Fertilizante Viva (via foliar) & $\mathrm{L}$ & 14,10 & 10,00 & 141,00 & 366,60 \\
\hline $\begin{array}{l}\text { Fertilizante Hidrocoquetel (via } \\
\text { foliar) }\end{array}$ & $\mathrm{kg}$ & 35,72 & 6,00 & 214,32 & 557,23 \\
\hline Fertilizante Hidroferro (via foliar) & $\mathrm{kg}$ & 37,21 & 6,00 & 223,26 & 580,48 \\
\hline Subtotal B & & & & $16.581,53$ & 43.111,97 \\
\hline C - DIVERSOS & & & & & \\
\hline Frete & & & & 600,00 & $1.560,00$ \\
\hline Exames (folha,raiz e substrato) & & & & 480,00 & $1.248,00$ \\
\hline Assistencia técnica & & & & $1.207,68$ & $3.139,97$ \\
\hline Subtotal C & & & & $2.287,68$ & $5.947,97$ \\
\hline Custo operacional efetivo (C.O.E) & & & \multirow{6}{*}{\multicolumn{2}{|c|}{$\begin{array}{l}26.744,21 \\
1.337,21 \\
2.800,00 \\
1.170,06 \\
32.051,47 \\
32.051,47\end{array}$}} & $69.534,93$ \\
\hline Outras despesas & & & & & $3.476,75$ \\
\hline Depreciação do viveiro & & & & & 7.280 .00 \\
\hline Juros de custeio & & & & & $3.042,15$ \\
\hline Custo operacional total (C.O.T) & & & & & $83.333,83$ \\
\hline CUSTO TOTAL & & & & & 83.333 .83 \\
\hline
\end{tabular}

Tabela 2: Índice de lucratividade.

Quantidade inicial de mudas

\begin{tabular}{l|l} 
(unidade) & 24.000 \\
Perdas (\%) & 15 \\
Produçáá(unidade) & 20.400 \\
Preço médio/muda de primeira (R\$) & 3,20 \\
Preço médio/muda de segunda (R\$)* & 0,80 \\
Renda Bruta (R\$) & $60.384,00$ \\
Custo Operacional Total (R\$) & $32.051,47$ \\
Lucro Operacional (R\$) & $28.332,53$ \\
Índice de Lucratividade (\%) & 46,92 \\
Ponto de Equilíbrio (R\$) & 1,5712
\end{tabular}

* $10 \%$ das mudas efetivamente produzidas 


\section{CONCLUSÃO}

Analisando os resultados do trabalho, pode-se concluir que a produção de mudas cítricas no município de Monte Azul Paulista mostra-ser uma atividade rentável, tendo, portanto, um custo de produção satisfatório e uma relação benefício maior que a relação custo.

\section{REFERÊNCIAS}

AMARO A.A.; SALVA R.A. Produção de mudas cítricas em São Paulo: uma visão econômica. Informações econômicas, v.31, n.10, 2001.

FUNDECITRUS Manual de produção de mudas cítricas. Disponível em: <http: \www. fundecitrus.com.br> Acesso em: 20 jan. 2001.

GHILARDI, A.A. et al. Citricultura paulista: exigência física de fatores de produção, estimativa de custo e evolução das técnicas agrícolas. Informações econômicas, v.32, n.9, 2002.

POZZAN, M.; KANASHIRO, M. Custo da muda cítrica em viveiro telado. Agrianual, p. 250 $-253,2004$. 